\title{
Anibal Quijano (1930-2018), Instituto de Estudos Avançados e o contexto peruano ${ }^{1}$
}

ENRIQUE AMAYO ZEVALLOS ${ }^{I}$

\author{
Al fin de la batalla, \\ $\Upsilon$ muerto el combatiente, vino hacia él un hombre \\ $\Upsilon$ le dijo ;No mueras, te amo tanto! \\ Pero el cadáver ;ay! siguió muriendo...2
}

\section{Introdução}

$\Lambda$

ORIGEM deste trabalho é um e-mail que encaminhei a Carlos Guilherme Mota, informando com tristeza que o sociólogo peruano Aníbal Quija-

no ${ }^{3}$ havia falecido em Lima, no dia 31 de maio de 2018. No e-mail, lembrava que, graças a Carlos Guilherme, Aníbal havia passado um período como professor convidado do Instituto de Estudos Avançados da Universidade de São Paulo (IEA-USP). Carlos Guilherme respondeu-me sugerindo redigir uma nota informativa.

O objetivo deste texto é lembrar como chegou Aníbal ao IEA, fornecer alguma informação sobre o contexto peruano de sua formação, bem como assinalar alguns dos vínculos que ele estabeleceu em São Paulo.

Como professor aposentado da Unesp (onde continuo como professor voluntário), estou presentemente em San Diego, Califórnia. Este trabalho escora-se principalmente em minha memória, sujeita a erros involuntários, especialmente em relação às datas.

\section{Contextualizando}

Aníbal Quijano nasceu a 17 de novembro de 1930, em Yanama, uma pequena vila dos Andes peruanos, na região (estado) de Ancash. Importa dizer que esse território foi parte da Civilização Chavin (uma das mais antigas da América que, como outras, precedeu os incas) construtora de sua cidade capital, Chavin de Huantar, aproximadamente no ano 1000 a.C. Importa também dizer que na minha conversa telefônica com Piero, filho de Aníbal, em 17 de julho de 1918, ele chamou minha atenção para o surpreendente fato de que seu pai morreu no mesmo dia e mês em que havia morrido seu avô, o pai de Aníbal, em 1970. Dia trágico não apenas para Aníbal, mas também para o Peru, já que naquele dia morreram, além de seu pai e outros familiares, aproximadamente 70 mil pessoas, 
vítimas do terremoto que mais matou, em âmbito mundial, na segunda metade do século XX. ${ }^{4}$

Carlos Guilherme, como diretor e fundador do Instituto de Estudos Avançados da USP, solicitou minha intermediação para convidar Aníbal a passar um período como professor convidado do IEA-USP, o que aconteceu em 1991-1992. Eu estava então, graças a um convite de Carlos Guilherme, no IEA como pesquisador, e seu diretor sabia que, como peruano, eu tinha a sorte de ter conhecido Aníbal e mantinha contatos com ele, desde que foi meu professor em Lima.

\section{Fundador do primeiro Programa de Sociologia do Peru}

Conheci Aníbal como seu aluno. Ele foi, em 1962, fundador do Departamento de Sociologia da Faculdade de Economia e Ciências Sociais (FECS), da Universidade Nacional Agraria de La Molina (UNALM). Criada em 1902, como Escola Nacional de Agricultura (ENA), em 1960 transformou-se em universidade, com cinco faculdades; a FECS era uma delas.

Pela sua origem, a ENA era eminentemente técnica e, até se transformar em universidade, seu papel essencial havia sido trabalhar em função dos interesses dos grandes fazendeiros de então. Estava voltada principalmente para os produtores modernos, exportadores de algodão e cana-de-açúcar, em sua maioria localizados na costa e componentes essenciais da então chamada Oligarquia, do período conhecido como República Aristocrática.

Ao se transformar em universidade, o seu papel mudou. Passou a trabalhar e pesquisar também os produtos vegetais e animais originários dos Andes, ${ }^{5}$ muitos endêmicos, como: batata, ${ }^{6}$ tomate, quinoa, algodões de cores, totora (irmã do junco e fundamental para a navegação pré-colombiana de curta e longa distâncias, até transoceânica), coca (considerada sagrada pelas civilizações pré-colombianas), lhamas, chinchilas etc.

Aqui não é lugar para continuar aprofundando esse tema, mas importa dizer que, transformada em universidade, a UNALM precisava, em consonância com seus princípios orientadores (Colere Cupio Hominem et Agrum / Quero estudar o homem e o campo), entrar no território das Ciências Sociais, para estudar e pesquisar também a situação econômica e social do Mundo Andino. Para isso criou-se a FECS e Aníbal foi contratado como professor para fundar, em 1962, o Departamento de Sociologia. Dessa forma, ele tornou-se também o primeiro a estabelecer a profissão de sociólogo no Peru.

Ingressei na UNALM em 1962 e, de imediato, matriculei-me naquele novíssimo Departamento. Desde então mantive relações com Aníbal que, sem dúvida, foram essenciais para minha formação profissional. Esse Departamento terminou acolhendo o mais importante da pesquisa e do pensamento econômico-social peruano de então. Muitos são os exemplos de pesquisadores e pensadores eminentes que por lá passaram e entre eles importa mencionar o etnólogo e romancista essencial da questão indígena, não apenas do Peru, José Maria Ar- 
guedas. E o Departamento de Economia da FECS tinha entre seus professores, por exemplo, o agrônomo e economista Carlos Malpica, autor de Los dueños del Perú.

Desde suas origens, o Departamento de Sociologia e a FECS posicionaram-se de maneira crítica, com respeito à ordem estabelecida no Peru, exercendo influência na formação da opinião pública nacional. Isso provocava ressentimentos nos setores hegemônicos da UNALM, conformada por carreiras voltadas para formar engenheiros agrônomos, agrícolas e zootecnistas e, portanto, majoritariamente constituída por professores das chamadas ciências duras, como matemática, física, química e ciências biológicas. Para a maioria deles, as Ciências Sociais simplesmente não eram ciências. Nessa situação, Aníbal, em 1964, terminou sendo considerado uma espécie de líder dos pensadores críticos na universidade e acusado de coisas do tipo: "sempre chega ao campus perto das 11 horas, o que é um mau exemplo, pois chega tarde". Assim, contra a opinião e sob protesto da maioria dos professores e alunos da FECS e de muitos das outras faculdades, uma comissão nomeada pela reitoria determinou sua expulsão.

A expulsão acabou por ser providencial, pois liberou Aníbal para ser aceito como professor da Universidad Nacional Mayor de San Marcos, fundada em Lima em 1551, a mais antiga universidade de nosso continente. Pouco depois, foi nomeado para uma posição na Divisão de Assuntos Sociais da Comissão Econômica para América Latina (Cepal), no Chile, o que contribuiu para dar a seu trabalho alcance e reconhecimento internacionais. É bom lembrar que a Cepal, nos anos 1960 e 1970, passou pelo seu período de ouro, concentrando parte do melhor das Ciências Econômicas e Sociais da América Latina. Aníbal trabalhou ali com brasileiros como Fernando Henrique Cardoso e Francisco Weffort, entre outros. Assim, fez parte dos chamados Teóricos da Dependência, mas com produção de uma versão própria e original daquela abordagem, evidente em trabalhos como Redefinición de la dependência y processo de marginalización en América Latina.

O período de Aníbal na UNALM foi fundamental para a elaboração de alguns trabalhos que, desde cedo em relação ao conjunto de sua obra, evidenciam seu interesse por temas que o preocupariam ao longo de toda sua carreira. Por exemplo, é de 1964 seu trabalho Imagen saintsimoniana de la sociedad industrial, no qual assinala que a caraterística de inovação, imanente a essa sociedade, fatalmente gera contradições com impactos na urbanização. Tal ponto de partida, com desenvolvimentos através do tempo, conformaria parte de uma problemática tratada em seus trabalhos posteriores como Dependencia, cambio social y urbanización en América Latina (1968), Polo marginal y mano de obra marginal en América Latina (1970) etc.

Em 1965 publica Imagen y tareas del sociólogo en la sociedad peruana, obra marcada pela crítica teórica ao funcionalismo, pelo compromisso com mudanças para uma sociedade sem classes e sem exploração e pela defesa permanente de 
princípios éticos, que claramente mostram a influência, essencial em sua obra, do marxismo de José Carlos Mariátegui. ${ }^{7}$ Dessa linhagem são trabalhos posteriores como: Alternativas de las Ciencias Sociales en América Latina (1972), Notas sobre los problemas de la investigación social en América Latina (1990) etc. Também em 1965 completa sua tese: La emergência del grupo cholo y sus implicaciones en la sociedad peruana, na qual trata da violenta e complexa problemática étnico-social do Peru. Dessa linha serão trabalhos posteriores como "Notas sobre a questão da identidade e nação no Peru” (Quijano, 1992) etc.

$\mathrm{O}$ interesse de Aníbal pela questão cultural, racial, e de violenta desigualdade econômico-social não ficaria restrita apenas ao Peru, uma vez que sua obra torna evidente que, no âmbito social interno americano e mundial, tais questões apareceram como consequência da conquista e destruição da América Indígena pela Europa, no período de origem do capitalismo moderno. Essa premissa é fundamental para a construção de seu conceito de Colonialidade, como a outra face, desconhecida e obscura, da Modernidade. Trata-se de conceito de longa duração, pois continua marcando a história das sociedades atuais, o que será tema de trabalhos como: Modernidad, identidad y utopia (1988), La modernidad, el capital y América Latina nacen en el mismo dia (1995), Colonialidady modernidad (1992), Colonialidad del poder y clasificación social (2000), Colonialidad del poder, eurocentrismo y América Latina (2000), ¿Bien vivir?.' Entre el “desarrollo" y la Des/Colonialidad del poder (2010) etc. ${ }^{10}$

\section{O contexto peruano}

A presença de Aníbal na UNALM coincidiu com um período de violenta luta social pela terra no Peru, com o surgimento de guerrilhas que, como uma de suas consequências, gerariam finalmente o governo militar do general Juan Velazco Alvarado e sua radical Lei de Reforma Agraria de 24.6.1969, ${ }^{11}$ que terminou com o poder da oligarquia. ${ }^{12}$

Em 1962, Hugo Blanco, agrônomo formado na Argentina, líder trotskista da Frente de Izquierda Revolucionaria (FIR) e organizador de sindicatos camponeses, foi obrigado, pela repressão das Forças Armadas a esses sindicatos, ${ }^{13}$ a se defender militarmente; isso aconteceu no Valle de la Convención, região de Cusco.

Em 1965, Luis de la Puente, influenciado pela Revolução Cubana, iniciou, em Sierra Pelada (também na Região de Cusco), a luta do Movimiento de Izquierda Revolucionaraia (MIR) contra o primeiro governo de Fernando Belaúnde (28.7.1963 - 3.10.1968). Também em 1965, na Amazônia peruana, Região de Madre de Dios (limítrofe com a região de Cusco), ${ }^{14}$ apareceram as guerrilhas, também influenciadas pela Revolução Cubana, do Ejército de Liberación Nacional (ELN). Em fins de 1965 as guerrilhas tinham sido derrotadas pelas Forças Armadas, com a maioria de seus líderes mortos (como de La Puente) ou presos (como Hugo Blanco e Hector Béjar, do ELN).

Costuma-se perguntar por que o governo militar de Velazco Alvarado (3.10.1968 - 29.8.1975), resultado de um golpe de Estado, editou uma lei de 
reforma agrária tão radical, expropriando as fazendas e transformando-as em cooperativas. Há uma resposta quase consensual no Peru. As tarefas repressivas das Forças Armadas obrigaram-nas a tomar contato com uma realidade que mal conheciam: a do mundo rural andino. Nessa situação, alguns militares de alta patente, como Velazco Alvarado, concluíram que aquele cenário era inacreditavelmente injusto e que as Forças Armadas não deveriam mais participar da repressão e sim de uma mudança de situação. Isso explicaria um dos slogans mais difundidos, ao se decretar a Reforma Agraria: "Campesino, el hacendado no comerá más de tu pobreza" "Camponês, o fazendeiro não comerá mais de sua pobreza”).

Como as guerrilhas tinham como eixo de sua luta a questão agrária e a UNALM era o centro peruano mais importante de estudo dos assuntos agrícolas, essa situação gerou um forte impacto no destino daquela universidade e da FECS.

\section{O suicídio do chefe do Departamento de Sociologia da UNALM impacta o país}

A Lei de Reforma Agrária mudou a história econômica e social não apenas da agricultura peruana. A maioria de professores da UNALM, das mencionadas carreiras técnicas dominantes, estava vinculada, direta ou indiretamente, aos grandes produtores agrários. A situação levou aqueles professores a buscar que a UNALM se posicionasse contra a Reforma Agrária, porque eliminava a propriedade dos fazendeiros. ${ }^{15}$ A FECS, e especificamente seu Departamento de Sociologia, de fato posicionou-se criticamente, porém não contra, como queria o setor conservador, e sim no sentido de que a Reforma teria que ter sido organizada de forma diferente. A diferença preconizada era a necessidade de horizontalidade, ou seja: de um processo de contato e consulta com os produtores diretos, os camponeses. Criticava-se a condução verticalizada, imposta de cima para baixo, espelhando a formação militar e sua ideia de cadeia de comando e obediência. A posição da FECS coincidia plenamente com as opiniões de Aníbal que, no Chile - e depois de 1972 no Peru, para onde retornou - escrevia uma série de trabalhos relacionados com o governo militar. ${ }^{16}$

Assim existia uma situação muito tensa na UNALM, que a obrigava a tomar posição frente ao governo. ${ }^{17}$ Em 1969 o chefe do Departamento de Sociologia da UNALM era José Maria Arguedas, etnólogo e romancista cuja opinião tinha importância nacional; amigo de Aníbal compartilhavam interesses comuns como cientistas sociais e na paixão pela literatura. ${ }^{18}$ Naquele ano, Arguedas estava afastado da universidade, para tratar de sua depressão, em Santiago do Chile, onde terminava o que seria seu último escrito O Zorro de Arriba e o Zorro de Abajo. ${ }^{19} \mathrm{O}$ romance, muito complexo, é também a crônica de um suicídio, pois retornou para concluí-lo e, quase de imediato, na sala onde exercia as funções de chefe do Departamento de Sociologia, disparou um tiro contra a cabeça, morrendo no dia 2 de dezembro de 1969. Seu último livro põe às claras as tensões 
que sofria, sentindo-se quase impotente. ${ }^{20}$ Depois de toda uma vida rendendo tributo à ação, confrontado com a possibilidade da inação, decidiu escolher o caminho da morte. ${ }^{21} \mathrm{O}$ governo tentou organizar oficialmente o seu enterro, ${ }^{22}$ mas o gesto não foi aceito pela viúva, ${ }^{23}$ que preferiu fazê-lo juntamente com as autoridades da UNALM.

\section{As Forças Armadas invadem a UNALM e o Departamento de Sociologia é fechado}

Nessa situação de crise, a UNALM foi invadida pelas Forças Armadas e a FECS foi fechada. ${ }^{24}$

Essa ação do governo visava não apenas eliminar um importante elemento crítico, mas também cooptar profissionais, os melhores qualificados do país, para levar à frente as reformas econômicas e sociais em andamento. Quase todos os professores que ficaram sem trabalho receberam ofertas para ingresso como funcionários no Ministério de Agricultura, Sistema de Propriedade Social (encarregado da reforma das empresas agrícolas e industriais), Instituto Nacional de Planejamento (INP) (cuja responsabilidade era racionalizar as atividades do Estado) etc.

Eu, pessoalmente, graduado em 1968, tendo iniciado em 1969 minha carreira como docente no Departamento de Sociologia, fiquei sem trabalho com seu fechamento, recebendo então a oferta para ser chefe da Reforma Agrária do sul do Peru (com sede em Cusco). Era muito jovem e, tendo consciência de que não reunia condições para assumir tamanha responsabilidade, recusei o convite. Mas muitos outros aceitaram, chegando alguns a serem assessores diretos do presidente, vice-ministros e membros do alto escalão. Grande parte desse pessoal egresso da FECS se concentrou no INP, onde eu viria a trabalhar de 1976 a 1980 .

Como se pode perceber, a situação era muito complexa e Aníbal tinha informação diária de seu andamento, o que aumentava seus desejos de retornar ao Peru, fato que constatei nas minhas visitas a ele em Santiago do Chile, em 1966 e 1969. No final de 1971, Aníbal retornou a Lima, mas então eu já havia saído para realizar estudos de pós-graduação no exterior. Minha relação com ele continuou através de correspondência, salvo no período em que voltei a viver no Peru (1976-1980), quando mantivemos reuniões frequentes. Tinha retornado para fazer trabalho de campo para a tese de Ph.D, que desenvolvia na Inglaterra sob a orientação de Eric Hobsbawm. A carta de recomendação de Aníbal havia sido determinante para que Hobsbawm me aceitasse como seu orientando, em 1974, no Birbeck College da London University.

\section{Sociedade e política, deportação}

\section{e Alianza Revolucionaria de Izquierda (ARI)}

Não se está aqui fazendo uma completa biografia intelectual de Aníbal: busca-se apenas oferecer um perfil de quem era esse homem que chegava ao IEA. Nesse sentido interessa mencionar que, retornando a Lima, ele fundou 
uma revista acadêmica que impactou os meios políticos e de pesquisa econômico-social peruana: Sociedad y Politica. Revista de Análisis y Debate Politico (1972-1983). Sua participação política, espelhada na revista, foi considerada extremista pelo governo, o que levou à sua deportação para o México, junto com Julio Cotler, outro sociólogo peruano reconhecido internacionalmente, em setembro de 1973.

Aníbal torna-se então professor da Universidad Autónoma de México, onde trabalhava um grupo importante de cientistas sociais, como o mexicano Pablo Gonzales Casanova, o brasileiro Ruy Mauro Marini, Julio Cotler, dentre outros. Retornou a Lima, em 1975, e continuou com suas atividades de pesquisa e participação política, tomando parte na formação da Alianza Revolucionaria de Izquierda (ARI) que apresentava, para as eleições de 1980, Hugo Blanco como candidato a presidente da República. ${ }^{25}$

A ARI, por um período, conseguiu agregar grande parte da esquerda peruana: trotskistas, partido comunista pró-União Soviética e pró-China etc. Aníbal foi assessor de Hugo Blanco para assuntos econômico-sociais. Mas a ARI durou pouco, devido a exigências extremas, ${ }^{26}$ impostas pelos assessores trotskistas chegados de Paris, dentre os quais tinha lugar de destaque Luis Favre, ${ }^{27} \mathrm{e}$ às quais Hugo não conseguiu resistir. Assim a ARI se desintegrou e a esquerda peruana perdeu sua oportunidade histórica de chegar ao poder pacificamente. Levantamentos de opinião pública indicavam que Blanco tinha grande possibilidade de vitória eleitoral. ${ }^{28}$

\section{O professor de Cálculo da UNALM se transforma em ditador e Anibal se demite}

Os governos posteriores ao período militar (segundo governo de Belaúnde 1980-1985, primeiro de Alan García 1985-1990, três de Alberto Fujimori, 1990-2000) assumiram o papel essencial, com ritmos diferentes, de desmantelar as reformas e instituições ${ }^{29}$ criadas pelos militares. Essa situação originou insegurança e medo na população, sentimentos instrumentalizados pelo Sendero Luminoso, que se definindo como maoísta ${ }^{30}$ oferecia como solução, destruir $o$ Estado Feudal Peruano com a Guerra Popular que, até a vitória final, teria que atravessar um rio de sangue ${ }^{31}$. Isso acontecia $\mathrm{em}$ meio a uma profunda crise econômica.

Os anos 1990 foram chamados pela Cepal de "A década perdida da América Latina" e o Peru, devido à sua guerra interna, foi dos que mais perderam. Como indicador dessa crise estava a inflação que, no final do governo de Alan García, chegou ao nível de hiperinflação, ombreando com as mais altas do mundo.

Nesse contexto, para as eleições de 1990, o candidato Mario Vargas Llosa confrontou um quase desconhecido da população peruana, o professor de Cálculo e reitor da UNALM, Alberto Fujimori, filho de japoneses. ${ }^{32}$

As campanhas presidenciais dos dois candidatos centraram-se nos problemas mais sentidos pela população: insegurança e hiperinflação. Em relação à 
questão da segurança, os dois candidatos coincidiam em estratégia: propunham militarização e repressão crescentes, com a tendência, por parte de Fujimori, a outorgar poder determinante aos serviços de inteligência (que então não incluíam a Polícia Nacional). Quanto à hiperinflação, Vargas Llosa apresentava propostas neoliberais para sua eliminação.

Fujimori então mostrou ser calculista pois, sem se comprometer, sugeria que estava contra as medidas propostas por seu rival eleitoral. Esse posicionamento foi determinante para a vitória de Fujimori, pois Vargas Llosa não escondeu que suas medidas para eliminar a hiperinflação passavam pela liberação dos preços. Vargas Llosa perdeu as eleições e Fujimori mostraria, quase desde o início de seu mandato, que não tinha escrúpulos quando de poder se tratava. ${ }^{33}$ Uma vez eleito, Fujimori aplicaria medidas mais radicais que as defendidas por Vargas Llosa, a que chamaria de sinceramiento. A gasolina subiria quase $3.000 \%$, os alimentos, em torno de $500 \%{ }^{34}$

Em termos políticos, a luta de Fujimori contra as organizações terroristas, sempre assessorado por Montesinos, ${ }^{35}$ seria funcional às suas aspirações crescentemente ditatoriais que culminariam, em 5 de abril de 1992 , com o fechamento do Congresso.

Fujimori aos poucos controlaria, através do SIN, todos os setores do poder. Mas até então, a Polícia Nacional mantinha sua independência e realizava operações autônomas, entendendo que, para os planos de Fujimori e Montesinos, não convinha eliminar o Sendero Luminoso, ${ }^{36}$ porém que destruir esse partido terrorista era fundamental para o futuro do país. Por isso, sem informar a Fujimori nem a Montesinos, a Polícia Nacional, ${ }^{37} \mathrm{em} 12$ de setembro de 1992, localizou e invadiu uma reunião secreta, capturando os membros do Comitê Central do Sendero Luminoso, incluindo seu líder máximo, Abimael Guzmán. Foi o fim do Sendero Luminoso.

Nesse contexto político-ideológico, Aníbal chega ao Instituto de Estudos Avançados (1991-1992). No Peru ele ainda continuava como professor na Universidad Nacional Nacional Mayor de San Marcos que na época, como quase todas as universidades nacionais (federais), era considerada pelo governo como um centro de recrutamento político-ideológico, principalmente para o Sendero Luminoso. Assim as Forças Armadas terminaram, em 1995, invadindo a Universidad Mayor de San Marcos, o que levou Aníbal a denunciar essa violência em artigos jornalísticos como "El Fujimorismo y el Perú"; "Las manos sobre la universidad"; "Educación y democracia: la misma batalla", e outros. Aníbal demitiu-se da San Marcos mas continuou publicando artigos de denúncia da ditadura, sendo o último que conheço "Las ultimas elecciones del fujimorismo" (de 2000).

\section{Concluindo: Anibal no IEA}

Esse era o Aníbal que eu conheci e que Carlos Guilherme Mota me pediu para contatar e convidar. Aníbal aceitou o convite e no período em que ficou no IEA-USP, Carlos Guilherme, em convênio com o Memorial da América Latina 


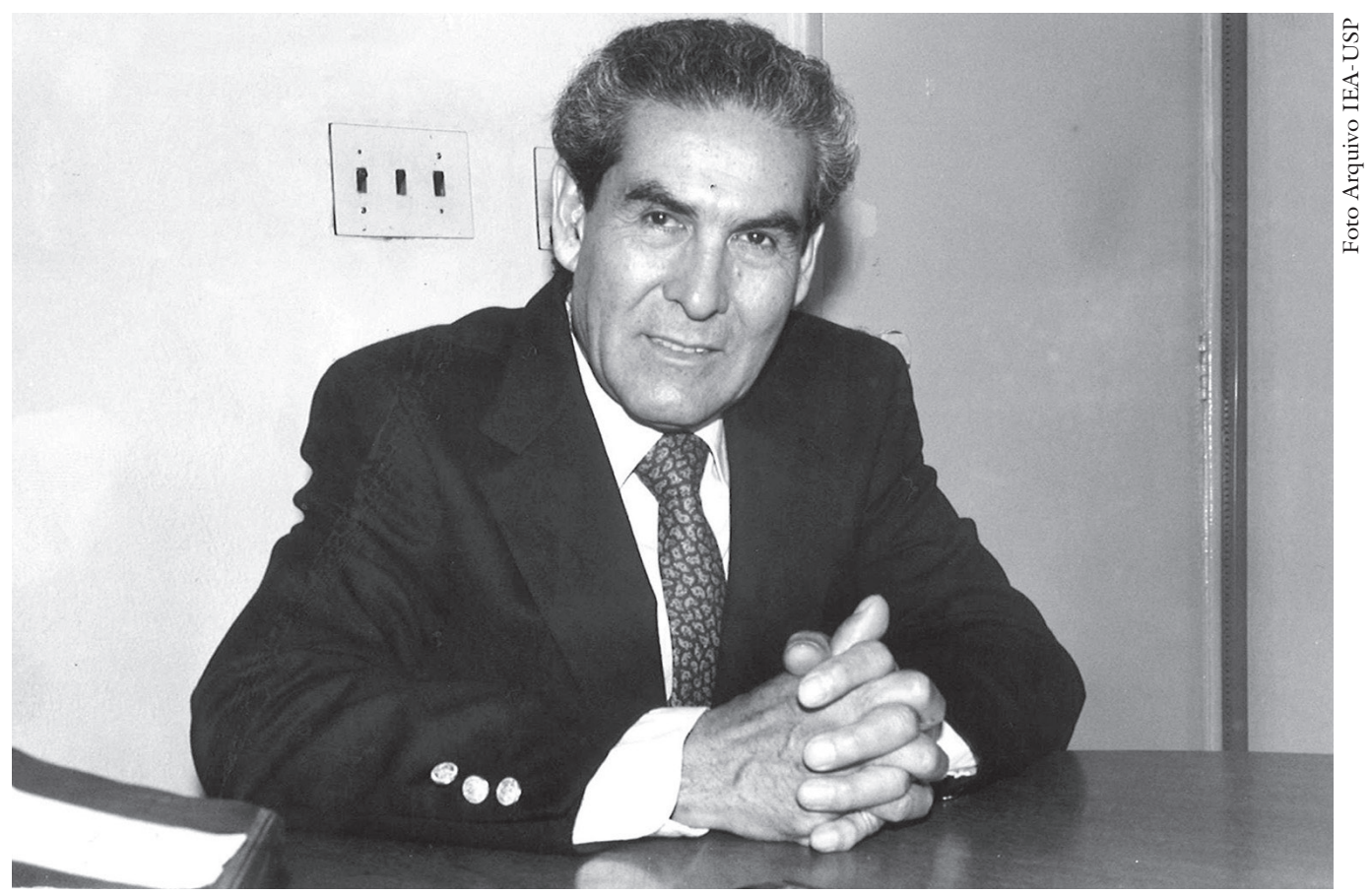

O Professor Aníbal Quijano no Instituto de Estudos Avançados da USP.

(facilitado porque então nosso amigo comum António Marcio Fernandes Costa, da Unesp, era diretor do Centro de Estudos Latino-Americanos do Memorial), fundou a Cátedra de Estudos Latino-Americanos Simón Bolívar. Aníbal foi o primeiro titular dessa cátedra.

Com Aníbal em São Paulo, sugeri ao pró-reitor de Pós-Graduação e Pesquisa da Unesp, Antônio Manuel dos Santos Silva, de quem eu era assessor, que o convidasse para desenvolver um curso de curta duração na reitoria. $\mathrm{O}$ curso foi ministrado e voltado para professores e alunos de pós-graduação das áreas de economia e ciências sociais dos diversos campi da Unesp.

Nesse mesmo período, desenvolveu também relações com a PUC-SP, especialmente com o núcleo de pesquisas da professora Regina Gadelha que, em seguida à sua morte, publicou um excelente trabalho sobre sua vida e obra. ${ }^{38}$

Como a visita de Aníbal ao IEA repercutiu em diversos setores acadêmicos da USP, posteriormente professores do Departamento de Geografia, organizadores do X EGAL - Encontro de Geógrafos da América Latina: por uma geografia latino-americana, convidaram-no para fazer a palestra de abertura daquele evento, realizado entre 20 e 25 de março de 2005. Aníbal (2005) aceitou o convite e sua palestra "Don Quijote y los Molinos de Viento en la América Latina" foi publicada na revista do IEA.

Aníbal participou de vários outros eventos na USP. Dentre eles, lembro sua participação no XXI Congresso da Associação Latino-Americana de Sociologia, realizado em 1997, porque entre seus organizadores estavam membros do IEA. 
Anoto um momento especial de felicidade de Aníbal. Foi quando recebeu informação da publicação de seu trabalho, realizado em coautoria ${ }^{39} \mathrm{com}$ Wallerstein: "La americanidad como concepto, o América en el moderno sistema mundial", apresentado no Simpósio Mundial pelo $500^{\circ}$ Aniversário da América, organizado pela Unesco, em Paris, em outubro de 1992.

Finalizo lembrando que em meu e-mail a Carlos Guilherme, que originou este trabalho, eu terminava sugerindo que fosse organizada, no IEA-USP, uma Mesa de Trabalho em Memória de Aníbal Quijano, propondo que entre os organizadores estivesse também o professor Sedi Hirano, outro grande amigo de Aníbal na USP.

San Diego, agosto 2018.

\section{Notas}

1 Agradeço a meu amigo Marcos Palacios, Ph.D., professor da Faculdade de Comunicação da Universidade Federal da Bahia (UFBA), pela revisão do texto.

2 "Ao fim da batalha, / / E já morto o combatente, veio até ele um homem / / E disse // não morras, te amo tanto! // Mas o cadáver, ai! continuou morrendo...” Do soneto Masa, do poeta peruano César Vallejo (1892-1938). O Prêmio Nobel de Literatura Mario Vargas Llosa considera que outros dois escritores da América Hispana também mereciam o mesmo prêmio: Vallejo e Jorge Luis Borges. Disponível em: <https:// larepublica.pe/politica/488345-mario-vargas-llosa-vallejo-y-borges-merecieron-el-premio-nobel>.

3 O Conselho Latino-Americano de Ciências Sociais (Clacso), em 2014, publicou uma antologia essencial de sua obra, com 859 páginas (Quijano, 2014).

$4 \mathrm{O}$ terremoto mesmo matou relativamente poucas pessoas por felizmente ter acontecido perto das $15 \mathrm{~h} 30$ quando, normalmente, as pessoas estão acordadas e ainda mais nesse caso porque nesse horário começava o primeiro jogo do Mundial de Futebol de 1970 e a maioria de peruanos estava, como os brasileiros, assistindo à partida México-União Soviética. O terremoto fraturou a maior montanha tropical da Terra, o Huascarán, de 6.768 m (Patrimônio Natural da Humanidade, onde nasce o rio Maranhão, um dos que originam o Amazonas). O Huascarán fica em Ancash e abaixo de suas encostas existia (e ainda existe) um conjunto de pequenas vilas e cidades, como a bela Yungay (conhecida então como a capital do Andinismo peruano). A fratura lançou milhões de toneladas de gelo sobre aquela cidade e outras mais. Yungay foi soterrada, com a morte de quase todos os seus milhares de habitantes. Ali moravam o pai de Aníbal e outros familiares próximos. Dessa cidade, hoje lembrada com o título de Cementerio Nacional del Peru, restaram apenas as pontas das torres da Igreja da Sé. Disponível em: <https://elcomercio.pe/archivo-elcomercio/archivo/terremoto-callejon-huaylas-1970-noticia-523935>.

5 Importa dizer aqui que o Peru é um dos poucos lugares do mundo onde, de forma original e autônoma, aconteceu a Revolução Agrícola (há aproximadamente nove mil anos), seguida pela Revolução Urbana (há aproximadamente cinco mil anos), quando foi construída, perto da costa, a Cidade de Caral, a mais antiga da América e uma das mais antigas do mundo Disponível em: <https://whc.unesco.org/en/list/1269>. Tal acontecimento marca o início de uma série de civilizações agrícolas-pesqueiras 
que, quase 4.000 anos depois, culminariam com a cultura incaica (aproximadamente de 1.200 a 1.532 d.C).

6 Por exemplo em 1971 graças à UNALM fundou-se, em Lima, El Centro Internacional de la Papa (CIP) (Papa é o nome em quéchua, idioma dos incas, da batata) para pesquisar esse tubérculo que é um dos mais importantes alimentos da humanidade, assim como a batata doce (ou Camote em Aymará, idioma dos habitantes da Bacia do Lago Titicaca), ambas originárias dos Andes. Disponível em: <https://cipotato.org/ es/>.

7 Existe consenso de que Mariátegui (1895-1930) foi um pensador marxista original, fiel a seu princípio de nem decalque e nem cópia, mas criação heroica. Sua influência, essencial desde cedo na obra de Aníbal, pode ser deduzida do grande número de trabalhos que lhe dedicou como: Ensayos escogidos de José Carlos Mariátegui (1956), El marxismo en Mariátegui: una propuesta de racionalidad alternativa (1995); Raza, Etnia y Nación en Mariátegui: cuestiones abiertas (1992) etc. Além disso, faz-se necessário lembrar que Aníbal foi editor do Anuario Mariateguiano revista cujo objetivo era estudar a influência nacional e internacional da obra de Mariátegui. Disponível em: <http://bdigital.uncu.edu.ar/objetos_digitales/1636/beigelcuyol4.pdf>.

8 Cholo no Peru atual é um conceito étnico-cultural. No período colonial (1532-1821), como parte da classificação racista que se generalizava mundialmente, significou a mistura do indígena e branco para inferiorizar o grande número resultante. Com o tempo mudou e, na atualidade, indigena é quem fala só idiomas nativos, como o quéchua (aproximadamente 4,5 milhões), ou aymará (mais ou menos 600 mil) ou algum dos outros 45 idiomas nativos, perfazendo um total aproximado de sete milhões de indígenas peruanos. Assim o indígena que aprende e fala também o espanhol, passa ao status de cholo (caso do ex-presidente Alejandro Toledo). No Peru, etnicamente a maioria dos que se consideram brancos são, na realidade, "brancos" que, no período da Republica Aristocrática, eram minoria mas hegemônicos, e os cholos (já então maioria junto aos também misturados descendentes de africanos, chineses, japoneses etc.) não tinham acesso ao poder. A classificação como cholo era pejorativa. Na atualidade, crescentemente os peruanos se reconhecem como cholos e para que isso tenha acontecido os trabalhos de Aníbal, e principalmente de Arguedas, foram muito importantes. Mas o determinante foi o governo de Velazco Alvarado, como se verá mais adiante.

9 O conceito de Bien Vivir tem remota origem na Nueva Crónica y Buen Gobierno. Esse texto foi originalmente produzido como uma carta ao rei de Espanha, Felipe III, escrita provavelmente entre 1585-1610, pelo intelectual indígena Felipe Guamán Poma de Ayala, que sobreviveu à conquista espanhola convencido de continuar desenvolvendo seu papel dos Amauta. O termo Amauta, em quéchua, significa, aproximadamente, Mestre ou Sábio que tem por obrigação passar conbecimentos aos que não sabem. Para Poma de Ayala, a destruição de sua sociedade era consequência do Mal Governo do Vice-Reinado Peruano porque o rei espanhol, estando distante, não sabia o que estava acontecendo naquelas terras. Poma de Ayala sentia-se na obrigação de passar-lhe informação objetiva, pois estava convencido de que o Rei tinha que governar como o Inca que, tendo um sistema de informação permanente sobre tudo o que acontecia em seus domínios (os Amautas formavam parte desse sistema), Governava Bem Uma Sociedade Justa. Escreveu quase 1.200 páginas, ilustradas com centenas de desenhos. A carta, encaminhada provavelmente em 1615, perdeu-se no caminho. Em 1910, foi encontrada na Biblioteca Real da Dinamarca, abrindo-se assim um caminho extraordi- 
nário para o conhecimento da sociedade indígena (não só peruana) que, sem dúvida, tinha uma racionalidade diferente da Ocidental. O texto de Guamán Poma contribuiu para estender o mito da Sociedade Inca como Sociedade Socialista. Mas também, o que é essencial, foi um dos determinantes para abrir um outro capítulo da História como disciplina, a História dos Vencidos.

10 A universidade privada "Ricardo Palma", de Lima, abriu para Aníbal a Cátedra América Latina y la Colonialidade del Poder. Disponível em: <http://www.urp.edu.pe/ catedras_urp/index.php?urp=colonialidad $>$.

11 A escolha da data não foi fortuita, pois 24 de junho, para os incas, era seu dia mais importante, celebrado com uma grande festa para homenagear o Inti Raymy (Deus-Sol), coincidindo com o Solstício de Inverno no Hemisfério Sul. No Período Republicano (depois de 1821), essa data foi denominada Dia do Índio e declarada feriado nacional.

12 Os fazendeiros eram parte essencial da classe dominante e estavam divididos em dois grupos principais. Um conformado pelos que produziam para exportar, localizados principalmente na Costa, com métodos de produção vinculados a relações salariais; eram considerados modernos e chamados de Oligarcas. Outro constituído por produtores para o mercado interno, estabelecidos principalmente na Serra Andina, com métodos de produção vinculados a relações pré-capitalistas; eram considerados tradicionais e chamados de Gamonales. Os últimos têm semelhanças com os coronéis brasileiros.

13 O Peru tinha então um governo resultante de um golpe de Estado, encabeçado por um ditador violento, o general Ricardo Pérez Godoy (18.7.1962 - 3.3.1963).

14 Não deve causar surpresa que as guerrilhas tenham aparecido nesses territórios pois eles, historicamente, conformaram o coração do Mundo dos Incas, assim como o eixo a partir do qual foi irradiada a conquista espanhola. A conquista deixou um território onde a superexploração do trabalho dos camponeses, na sua maioria descendentes dos incas, era a norma. Assim, simbolicamente, não só para aqueles guerrilheiros, mas também para os peruanos que compartilhavam um pensamento progressista, Cusco e seus territórios limítrofes teriam que ser os primeiros liberados da superexploração.

$15 \mathrm{O}$ governo pagou a expropriação com Títulos do Estado, operação complexa sobre a qual não é possível tratar neste texto.

16 Por exemplo, em outubro de 1968, Aníbal, usando o pseudônimo Ramón Collar (nome de um camponês da Guerra Civil Espanhola que aparece num dos poemas de Vallejo sobre essa guerra, na qual participou defendendo a República), escrevia: "El golpe militar en el Perú en el contexto de la realidade peruana y latinoamericana" (publicada a mimeógrafo no Peru pelos alunos da FECS). Posteriormente, assinando com seu nome real, publicou: Nacionalismo, Neoimperialismo y Militarismo en el Perú (1971); La Reforma Agraria en el Perú (1973); La "segunda fase" de la "revolución peruana" y la lucha de clases (1975) etc. Por "segunda fase" se conhece o governo de Morales Bermúdes (29.8.1975 - 28.7.1980), que tenta reverter a maioria das reformas e termina convocando eleições presidenciais, ganhas por Belaúnde (28.7.1980 $-28.7 .1985)$.

$17 \mathrm{O}$ governo mostrava-se crescentemente progressista pois, por exemplo, abriu relações com Cuba e os países socialistas quando, na situação de guerra fria, isso significava o risco de confrontar os Estados Unidos. Em 1970 libertaria a Hugo Blanco, Hector Béjar etc., oferecendo-lhes cargos importantes no governo, o que foi aceito por mui- 
tos (como Béjar); os que não aceitaram (Hugo Blanco), foram deportados, no seu caso para o México.

18 Aníbal não é reconhecido como romancista ou poeta, mas sim como comentarista da literatura. Sua obra foi enriquecida por referências literárias, assuntos evidentes em trabalhos como: Antología del Cuento Latinoamericano (1957), Arguedas: la sonora banda de la sociedad (1984), "Dom Quixote e os moinhos de vento na América Latina” (2005), El nudo arguediano (2011) etc.

19 O zorro é a raposa. Francisco de Ávila, um dos sacerdotes espanhóis encarregados de perseguir e destruir as religiões indígenas (processo conhecido como Extirpação de Idolatrias, que só terminou com a Independência), em 1598, impressionado pelos relatos que escutava dos sacerdotes indígenas que torturava, coletou essas versões no texto Dioses y Hombres de Huarochiri. Originalmente em quéchua, seu tradutor para o espanhol, em 1966, foi Arguedas. Esse texto tem, para a história do Mundo Andino, importância similar à do Popol Vuh para a Mesoamérica ou do Livro dos Mortos para o Egito. Ali aparece o mito das duas raposas que, sendo deuses, podem à vontade se transformar em humanos. Uma é do mundo de cima (de arriba), das Serras Andinas e a outra é do mundo de baixo (de abajo), das Planícies Costeiras (ou Amazônicas). Essas raposas estão sempre, através do tempo, brincando e/ou lutando. Trata-se de uma boa síntese da real história andina pré-colombiana em que, às vezes e por longos períodos, civilizações da parte de baixo e da parte de cima, alternaram-se na hegemonia.

20 Cartas trocadas com Hugo Blanco, naqueles dias, mostram a angústia e sentimento de impotência de Arguedas pela manutenção de seu amigo na prisão, apesar das pressões que ele e outros estavam fazendo pela sua libertação (declarações, participação em marchas etc.). Arguedas mostrou ativa simpatia por todos os que lutavam pela terra. Alguns messes depois do suicídio, o governo de Velazco Alvarado libertou Hugo e outros guerrilheiros.

21 O que é evidente na sua Carta de Despedida. Disponível em: <http://www.lamolina. edu.pe/Gaceta/notas/arguedas.htm>.

$22 \mathrm{O}$ enterro quase paralisou Lima e o país. Os que carregamos o caixão tivemos a experiência marcante de caminhar junto a milhares de pessoas de todas as classes, etnias e idades (acompanhados, na parte de atrás, por um silencioso batalhão das Forças Armadas que compareceu, sem convite, a mando de um oficial de alta patente) muitas das quais, ao chegar ao cemitério, cantaram em espanhol, quéchua e outros idiomas indígenas. Sem dúvida foi um tributo ao romance de Arguedas Todas las sangres (Todos os sangues) que, de forma indireta, espelha o tipo de país que desejava.

23 A viúva, Sybila Arredondo, teria depois um filho com um militante da organização terrorista Sendero Luminoso, formando parte do círculo íntimo de Abimael Guzmán, líder do Sendero. A guerra, deslanchada principalmente por essa organização, mataria quase 70 mil pessoas (na sua maioria vítimas do Sendero, segundo a Comissão da Verdade e Reconciliação, criada pelo governo em junho 2001. Disponível em: <http://www.cverdad.org.pe/ifinal/pdf/Tomo\%20-\%20ANEXOS/ANEXO\%202. pdf $\geq$ ). Seus líderes terminaram na cadeia e Sybila, em 2002, depois del4 anos presa, foi deportada para o Chile, seu país de origem. O Sendero Luminoso não tinha simpatia por Arguedas, pois o considerava fraco, incapaz da violência armada. Ele, em diversas oportunidades, como na sua Carta de Despedida, negou la rabia (a raiva). Isso porque existe o mito de que a conquista gerou frustração nos descendentes dos conquistados que, através do tempo, transformaram essa frustração em raiva contida, 
a qual em algum momento explodiria violentamente. Arguedas não comungava com esse mito que o Sendero Luminoso tentou instrumentalizar.

24 Posteriormente seria reaberta, com o nome de Facultad de Economia y Planificación, mas sem Departamento de Sociologia.

25 A segunda fase do governo militar, encabeçado por Morales Bermúdez, foi recuando das reformas da primeira fase (Velazco Alvarado), ao tempo em que se preparava o retorno aos quartéis. Para isso, Morales Bermúdez convocou eleições para uma Assembleia Constituinte (AC), em 1978, e presidenciais em 1980. Hugo Blanco foi eleito membro da AC, com uma votação muito alta, transformando-se, de fato, no mais importante líder da esquerda peruana.

26 Então, anonimamente, Aníbal publicou: ARI: ¿Por qué y como se desintegró? ¿Quiénes son los responsables?

27 Trata-se do mesmo Favre que foi esposo de Marta Suplicy e que no Brasil é argentino, no Peru, brasileiro, na Argentina, francês etc. Esse aventureiro, acostumado a obter riqueza fácil, sequer usa seu nome para facilitar suas atividades e movimentações, o que se deduz do que foi escrito por um dos organizadores do ARI, o trotskista peruano Ricardo Napuri: Breve y sucia historia de Felipe Wermus, alias Luis Favre: Disponível e: <http://www.gatoencerrado.net/store/noticias/73/73210/detalle.htm>.

28 Mas Favre não desistiu do Peru, pois, segundo a imprensa daquele país, levado por Lula da Silva, tornou-se assessor da campanha eleitoral que conduziria Ollanta Humala à presidência (28.7.2011 - 28.7.2016). Disponível em: <https://www.americaeconomia.com/politica-sociedad/politica/ollanta-humala-ratifica-que-asesores-de-lula-da-silva-trabajan-en-su-coma>. Ollanta Humala teria recebido, do Departamento de Operações Estruturadas da Odebrecht, US\$ 3 milhões, graças a Lula que aprovou a doação (Revista Caretas, Lima, 23.2.2017: 15; meus itálicos). Humala terminaria na cadeia junto com sua esposa, depois de deixar a presidência (julho 2017-abril 2018) e agora, já em liberdade, continua processado como parte da operação Lava Jato peruana. Posteriormente, Favre prestaria assessoria à prefeita de Lima, Susana Villarán, processada por ter recebido, no período dessa assessoria, US\$ 3 milhões das empreiteiras Odebrecht e OAS. Disponível em: <https://larepublica.pe/politica/1222566-fiscalia-afirma-que-villaran-se-hipoteco-a-odebrecht-y-oas-por-us-3-millones $>$.Finalmente, a Lava Jato peruana, que investiga a Odebrecht (que transformou Lima no centro de suas operações para América Latina) e outras empresas brasileiras, começou a interrogar Favre em Paris. Disponível em: <https://elcomercio.pe/politica/fiscalia-interrogo-14-horas-publicista-luis-favre-paris-noticia-540177>.

29 Uma das instituições que mais resistiram foi o INP, devido ao seu prestígio e reconhecimento público como agente que racionalizava as atividades do Estado. Exatamente por tal razão, tornou-se um empecilho para o programa ultraliberal que seria imposto por Fujimori. Assim, em meados de 1992, Fujimori dissolveria o INP, iniciando, quase simultaneamente, a venda das empresas estatais, a preços irrisórios, a capitalistas amigos nacionais e estrangeiros.

30 Aqui só é possível dizer que nesse particular o Sendero Luminoso foi acompanhado pelo seu inimigo ideológico, o Movimiento Revolucionario Túpac Amaru (MRTA) (influenciado pela Revolução Cubana), que iniciou suas atividades em 1982 e foi desarticulado em 22.4.1997, quando as Forças Armadas recuperaram a embaixada de Japão, que tinha sido invadida por esse grupo guerrilheiro. 
31 Tarefa que, segundo a Comissão e seu Museu da Verdade e Reconciliação de Lima, estava cumprindo fielmente, durante o período em que existiu (17.5.1980 - 12.9.1992).

32 Anos depois, Fujimori recuperaria sua nacionalidade japonesa. Peru é Unicameral com um Congresso composto por 120 representantes. Para ser eleito pela terceira vez consecutiva em 2000, Fujimori conseguiu uma interpretação favorável pela maioria dos congressistas, contra a Constituição, que não permitia terceiro mandato. Essa maioria foi conseguida pela compra de congressistas (antecedendo o mensalão brasileiro), através de Vladimiro Montesinos, chefe do ultrapoderoso Servicio de inteligência Nacional (SIN) e sócio de Fujimori. A compra dos votos foi descoberta e denunciada pela TV. Montesinos fugiu e, gradativamente, a situação de Fujimori, principalmente pela pressão popular, tornou-se difícil. No dia 13 de novembro de 2000, usando o avião presidencial, em que levava quase 100 grandes malas (com milhões de dólares além de documentação confidencial, segundo a imprensa peruana), Fujimori partiu com destino a Brunei, para a reunião da Organização Económica Ásia e Pacífico (APEC) da qual o Peru é membro. No dia 19 de novembro, fugiu para o Japão e ali, ao mesmo tempo em que era acolhido obtendo imediatamente a nacionalidade, por fax comunicou sua renúncia à presidência, que foi aceita pelo Congresso peruano devido à sua evidente incapacidade moral. No Japão, recebido pelo imperador, Fujimori tornar-se-ia membro do partido de direita e candidato a senador.

33 Fujimori chegou a permitir a tortura de sua esposa, Susana Higuchi, pelo SIN de Montesinos, dentro do Palácio do Governo. Ela havia feito declarações à imprensa demonstrando sua insatisfação com um dos irmãos de Fujimori que estava vendendo, para enriquecer, o que chegava do Japão como parte dos programas de ajuda. Isso deslanchou as torturas que a enlouqueceram. Disponível em: <https://larepublica.pe/ politica/916019-susana-higuchi-al-congreso-si-senor-presidente-sufri-torturas-con-electroshock>. Nessa situação, Fujimori, sem primeira dama, nomeou para esse posto a sua filha Keiko, que assim iniciou sua carreira política quase literalmente por cima do cadáver de sua mãe. Ainda que seja difícil de entender, para a lógica orientada pela decência, hoje Keiko é líder do partido fujimorista Fuerza Popular (FP), que domina o Congresso, provavelmente o mais corrupto da história republicana peruana. Infelizmente assuntos políticos dessa ordem, quase incompreensíveis, acontecem também em outros países, não só sul-americanos.

34 Disponível em: <http://cienciashistoricossociales.blogspot.com/2010/11/fujimori-el-neo-liberalismo-y-el.html>.

35 Aqui só é possível agregar alguns detalhes elucidativos sobre o período. É fato que o governo de Alberto Fujimori foi feito em associação estrutural com Montesinos, o que explica roubos e desvios compartilhados por ambos que, é consensual, chegariam a bilhões de dólares. Por diversos crimes terminaram na cadeia: Fujimori, em 3.1.2010, foi condenado a 25 anos de prisão e o mesmo aconteceu com Montesinos, em 1.10.2010. Em 24.12.2017, Fujimori foi indultado pelo presidente Pedro Pablo Kucsynski. O indulto foi resultado de uma negociação secreta: em troca da liberdade de Fujimori, Kucynski obteria apoio do grupo de congressistas fieis a Kenji Fujimori (irmão de Keiko, com quem está em guerra pelo domínio da maioria no Congresso). Fujimori conseguiu a liberdade, mas a negociação foi descoberta, o que levou Kuscynski a renunciar, em 21.3.2018, sendo também processado pelos seus negócios obscuros com a Odebrecht. Fujimori pode retornar à cadeia, pois continuam processos contra ele por crimes de lesa humanidade, que o indulto não cobriu. 
36 O Sendero Luminoso era certamente muito mais perigoso que o Movimiento Revolucionario Túpac Amaru.

37 Ver Bowen e Holligan (2003). Uma das consequências dessa captura foi submeter a Polícia Nacional ao SIN e castigar, de diversas formas, os policiais que fizeram a captura.

38 Disponível em: <https://zimbra.fclar.unesp.br/service/home/ / ?auth=co\&loc=pt_ BR\&id $=155141$ \&part $=2>$.

39 Aníbal foi professor da Universidade de Bighampton, Estados Unidos, desde os anos 1980, onde lecionava um trimestre acadêmico por ano. Naquela universidade trabalhava também um grupo de pesquisadores "marxo-braudelianos" como Immanuel Wallerstein, Giovanni Arrighi e outros, que são referências internacionais das Ciências Sociais.

\section{Referências}

BOWEN, S.; HOLLIGAN, J. El espía imperfecto. La Telaraña Siniestra de Vladimiro Montesinos. Lima: Editora Peisa, 2003.

QUIJANO, A. ARI: ¿Por qué y cómo se desintegró? ¿Quiénes son los responsables? Lima: Sociedad y Política Ediciones, 1980.

. Notas sobre a questão da identidade e nação no Peru. Estudos Avançados, São Paulo, v.16, n.16, p.73-80, 1992.

Dom Quixote e os moinhos de vento na América Latina. Estudos Avançados, São Paulo, v.19, n.55, p.9-31, 2005.

. Aníbal Quijano. Cuestiones y horizontes. Antología esencial. De la Dependencia Histórico-estructural a la Colonialidad/Descolonialidad del poder. Selección y Prólogo Danilo Assis Clímaco. Buenos Aires: Clacso, 2014 (Coleção Antologías).

RESUMO - A origem deste trabalho é um e-mail que encaminhei a Carlos Guilherme Mota informando, com tristeza, que o sociólogo peruano Aníbal Quijano havia falecido em Lima em 31 de maio de 2018. Graças a Carlos Guilherme, Aníbal passou um período como professor convidado do Instituto de Estudos Avançados (IEA) da Universidade de São Paulo. O objetivo deste trabalho é lembrar como chegou Aníbal ao IEA, fornecer alguma informação sobre o contexto peruano de sua formação, bem como assinalar alguns dos vínculos que então ele estabeleceu nos meios acadêmicos de São Paulo.

PALAVRAS-CHAVE: Aníbal Quijano, Instituto de Estudos Avançados da Universidade de São Paulo, Sociólogo, Peru, Contexto.

ABSTRACT - The idea for this paper came to me when I sent an email to Carlos Gilherme Mota informing him that, sadly, Peruvian sociologist Anibal Quijano had passed away on May 5, 2018, in Lima. Carlos Guilherme was responsible for Anibal's appointment as Visiting Professor at the Institute of Advanced Studies (IAS) of the University of Sao 
Paulo (USP). This paper intends to remember how Anibal came to the Institute, offer information on the Peruvian context during his career and point out some connections that he established with the academic milieu in São Paulo.

KEYWORDS: Anibal Quijano, Institute of Advanced Studies (IAS) of the University of São Paulo (USP), Sociologist, Peru, Context.

Enrique Amayo Zevallos é Ph.D pela University of London \& University of Pittsburgh; professor de História Econômica e Estudos Internacionais Latino-Americanos do Departamento de Economia, Programa de Pós-Graduação em Ciências Sociais. Fundador do Núcleo de Pesquisas sobre o Pacifico e Amazônia, Faculdade de Ciências e Letras, Unesp Araraquara; e professor do Programa de Pós-Graduação em Relações Internacionais “San Tiago Dantas”, Unesp, Unicamp, PUC-SP. @ - eazamayo@fclar.unesp.br Recebido em 28.8.2018 e aceito em 15.9.2018.

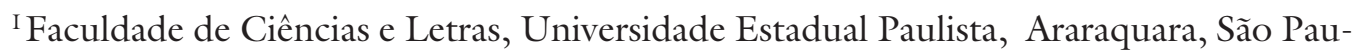
lo, Brasil. 
